\title{
Quantifying the consequences of nutritional strategies aimed at decreasing phosphorus excretion from pig populations: a modeling approach
}

\author{
V. Symeou, I. Leinonen and I. Kyriazakis ${ }^{\dagger}$ \\ School of Agriculture, Food and Rural Development, Newcastle University, Newcastle upon Tyne, NE1 7RU, UK
}

(Received 19 March 2015; Accepted 17 September 2015; First published online 6 November 2015)

\begin{abstract}
There is a global imperative to reduce phosphorous $(P)$ excretion from pig systems. In this study, a previously validated deterministic model was modified to be stochastic, in order to investigate the consequences of different management strategies on $P$ excretion by a group of growing pigs. The model predicts $P$ digestion, retention and excretion from feed composition and growth parameters that describe a specified pig phenotype. Stochasticity was achieved by introducing random variation in the latter. The strategies investigated were: (1) changing feed composition frequently in order to match more closely pig digestible $P$ (digP) requirements to feed composition (phase feeding) and (2) grouping pigs into light and heavy groups and feeding each group according to the requirements of their group average BW (sorting). Phase feeding reduced $P$ excretion as the number of feeding phases increased. The effect was most pronounced as feeding phases increased from 1 to 2, with a 7.5\% decrease achieved; the increase in phases from 2 to 3 was associated with a further $2.0 \%$ reduction. Similarly, the effect was more pronounced when the feed targeted the population requirements for digP at the average BW of the first third, rather than the average requirements at the mid-point BW of each feeding sequence plan. Increasing the number of feeding phases increased the percentage of pigs that met their digP requirements during the early stages of growth and reduced the percentage of pigs that were supplied $<85 \%$ of their digP requirements at any stage of their growth; the latter may have welfare implications. Sorting of pigs reduced $P$ excretion to a lesser extent; the reduction was greater as the percentage of pigs in the light group increased from 10\% to 30\% (from 1.5\% to $3.0 \%$ reduction, respectively). This resulted from an increase in the $P$ excreted by the light group, accompanied by a decrease in the $P$ excreted by the remaining pigs. Sorting increased the percentage of light pigs that met their dig $P$ requirements, but only slightly decreased the percentage of heavy pigs that met these requirements at any point of their growth. Exactly the converse was the case as far as the percentage of pigs that were supplied $<85 \%$ of their digP requirements were concerned. The developed model is flexible and can be used to investigate the effectiveness of other management strategies in reducing $P$ excretion from groups of pigs, including precision livestock feeding.
\end{abstract}

Keywords: phase feeding, phosphorus excretion, pig, sorting, stochastic model

\section{Implications}

Robust simulation models can help us to investigate the consequences of management strategies on nutrient excretion by livestock populations. One way to achieve this is through the use of a stochastic, as opposed to a deterministic approach, since the latter deals only with the 'average' animal. This was the approach taken to investigate the consequences of different management strategies on phosphorus excretion by a group of growing pigs. The modeling approach taken would allow development of tools that

\footnotetext{
${ }^{\dagger}$ E-mail: ilias.kyriazakis@newcastle.ac.uk
}

enable the quantification of the consequences of nutritional strategies, such as phase feeding and sorting.

\section{Introduction}

As well as phosphorus ( $P$ ) being the most expensive feed resource after energy and protein, its excretion is an important aspect of the environmental impact of livestock systems. The water soluble P excretion represents the highest potential risk for losses by runoff in agricultural fields, causing eutrophication (Maguire et al., 2005). Pigs contribute $~ 15 \%$ of the total diffuse P load from livestock to waters in Great Britain (White and 
Hammond, 2006); in North America the nutrient, including $P$, content of manure and the consequent impact on the environment are considered a major challenge for pig systems (Statistics Canada, 2006). It is therefore an imperative to develop strategies that minimize $P$ excretion from pig systems.

Although there may be some potential to reduce $P$ excretion by genetic means (Forsberg et al., 2003), reducing P excretion by nutritional and management means remains the most viable option (Kyriazakis et al., 2013). The objective of this paper was to apply a modeling framework to investigate the consequences of different nutritional management strategies on $P$ excretion by groups of pigs through simulation modeling. The strategies investigated were: (1) changing feed composition frequently in order to match more closely pig requirements to feed composition (phase feeding) and (2) grouping pigs and feeding them according to their group average BW (sorting).

In this study, a stochastic approach was used to take into account the variation between individual pigs and its effect on group P retention and excretion. Currently there are a limited number of stochastic or other individual-based models that may enable us to address questions about nutrient excretion from pigs systems (Ferguson et al., 1997; Knap, 2000; Schinckel et al., 2007; Brossard et al., 2009). Although the deterministic, individual-based model by Pomar et al. (2009 and 2011) is capable of dealing with $P$ and has addressed the consequences of phase feeding on nutrient excretion, there are currently no stochastic approaches that enable the prediction of $\mathrm{P}$ excretion in soluble and insoluble forms.

\section{Material and method}

\section{Single animal model description}

The dynamic, deterministic pig growth model of Wellock et al. (2003), as adopted by Symeou et al. (2014a) was used to predict the fate of dietary P in groups of pigs. Briefly, the model represented the limited ability of pig endogenous phytase activity to dephosphorylate phytate as a linear function of dietary calcium (Ca). Phytate dephosphorylation in the stomach by exogenous microbial phytase enzymes was expressed by a first-order kinetics relationship. The absorption of non-phytate $P$ from the lumen of the small intestine into the blood stream was set at $0.8 \mathrm{~kg} / \mathrm{kg}$ and the dephosphorylated phytate from the large intestine was assumed to be indigestible. The net efficiency of using digested $\mathrm{P}$ was set at $0.94 \mathrm{~kg} / \mathrm{kg}$ and assumed to be independent of BW (Kyriazakis, 2011). P requirements for both maintenance and growth were made simple functions of body protein mass, and hence functions of animal phenotype undigested $P$ was assumed to be excreted in the feces in both soluble and insoluble forms. For justification of the values of the model parameters and mathematical relationships, the reader is referred to Symeou et al. (2014a). The model was extensively evaluated by Symeou et al. (2014b) and was found to predict satisfactorily the quantitative pig responses, in terms of $\mathrm{P}$ digested, retained and excreted, to variation in $P$ supply, $\mathrm{Ca}$ and exogenous phytase supplementation.
The model operated in daily time steps, and considered pigs maintained in a thermo-neutral environment, growing from $30 \mathrm{~kg}$ BW until they reached a UK slaughter weight of $120 \mathrm{~kg}$ BW. No environmental stressors were assumed to operate on the pigs (Wellock et al., 2004). The main model inputs were: (1) pig growth traits, including initial state; (2) feed composition; and (3) feeding plan; while the model outputs for an individual pig were: (1) average daily gain (ADG); (2) body composition; (3) feed intake and (4) soluble and insoluble, and hence total $P$ excreted.

The initial state of the pig was described by its initial body weight (BW0), from which the chemical composition of the pig was calculated assuming that the pig had its ideal composition set by its genotype (Emmans and Kyriazakis, 2001). The potential rate of protein retention was determined by pig phenotype and current protein weight only. The maximum (potential) protein retention was then used to determine the potential gains of the other chemical components, including $P$ (Emmans and Kyriazakis, 1997; Wellock et al., 2003; Symeou et al., 2014a). Potential ADG was the sum of the potential gains of protein, lipid, ash (including P) and water. A total of $5 \%$ of the BW gain was assumed to be gut fill (Wellock et al., 2004).

Each pig was given access to a feed of a certain $\mathrm{P}$ content (see below). It was assumed that the pig will attempt to consume an amount of feed that will satisfy its energy and protein requirements for potential daily gain and maintenance (Kyriazakis et al., 1990; Kyriazakis and Emmans, 1999). The same regulation does not seem to apply for P (Pomar et al., 2006; Lopes et al., 2009). The amount of feed that allows the pig to meet its energy and protein requirements to be achieved was calculated from the current protein and lipid contents of the pig, and the composition of the feed. If the feed was deficient in $\mathrm{P}$ then the actual, as opposed to potential rates of $\mathrm{P}$ retention were calculated. Symeou et al. (2014a and 2014b) predicted the $\mathrm{P}$ digestion, retention and ultimately excretion in growing and finishing pigs of different genotypes, offered access to feeds of different $P$ content. The total $P$ excreted comprised of fecal and urine $P$. The feces contained both insoluble and soluble $P$, while urinary $P$ was only soluble (Jendza and Adeola, 2009; Selle et al., 2011). For a complete description of the model including inputs and outputs, see Symeou et al. (2014a and 2014b).

\section{Generating variation in pig growth}

The protein and lipid growth of a certain pig phenotype can be described by a Gompertz function with the following parameters (representing growth traits): protein content at maturity $\left(\operatorname{Pr}_{\mathrm{m}}, \mathrm{kg}\right)$, lipid content at maturity $\left(\mathrm{L}_{\mathrm{m}}, \mathrm{kg}\right)$ and the relative growth rate at the inflection point of the growth curve $\left(B\right.$, day $\left.^{-1}\right)$, in accordance with Ferguson et al. (1997), Knap (2000), Emmans and Kyriazakis (2001), Pomar et al. (2003) and Wellock et al. (2004):

$$
\begin{gathered}
\mathrm{dPr} / \mathrm{dt}=\operatorname{Pr} \times B \times \ln \left(\operatorname{Pr}_{\mathrm{m}} / \operatorname{Pr}\right) \mathrm{kg} / \text { day, and } \\
\mathrm{dL} / \mathrm{dt}=\mathrm{L} \times B \times \ln \left(\mathrm{L}_{\mathrm{m}} / \mathrm{L}\right) \mathrm{kg} / \text { day }
\end{gathered}
$$


where $\operatorname{Pr}$ and $\mathrm{L}$ are the body protein and lipid contents $(\mathrm{kg})$, respectively.

The parameters $\operatorname{Pr}_{m}, L_{m}$ and $B$ are able to account for both growth rate and body composition. However, it should be noted that these parameters are dependent on each other and therefore are heavily correlated. This would cause serious problems in stochastic simulations, unless the correlation is taken into account. This problem can be avoided by not using all these parameters (and their distributions) directly as inputs of the simulations, but instead modeling their functional relationships. With this approach, we used the parameter $\operatorname{Pr}_{\mathrm{m}}$ as a starting point, and described the other parameters as follows. The relative growth rate at the inflection point $(B)$ has been found to be related to $\operatorname{Pr}_{\mathrm{m}}$ as follows: $B=B^{*} / \operatorname{Pr}_{m}^{0.27}$ (Emmans and Fisher, 1986). Now, instead of $B$, the 'scaled rate parameter,' $B^{*}$, can be used as an independent input parameter, as long as its distribution is determined.

The other main growth parameter is $L_{m}$. Again, this is correlated with $\operatorname{Pr}_{m}$, simply because bigger animals (with high protein content) can be expected to have higher lipid content than smaller animals. Assuming that the parameter $B$ is the same for both protein and lipid growth (Emmans and Kyriazakis, 1997), the relationship between these two parameters can be simply written as $\mathrm{L}_{m}=\mathrm{LPr}_{\mathrm{m}} \times \mathrm{Pr}_{\mathrm{m}}$, where $\mathrm{LPr}_{\mathrm{m}}$ (lipid to protein ratio at maturity) is an independent parameter, the mean and variation of which can be used as inputs in stochastic simulations.

The mean values of these three parameters and their variation (SD) within a population of modern pig genotypes were estimated from literature as follows.

The mean and SD of $\operatorname{Pr}_{\mathrm{m}}$ was estimated from the study of Knap et al. (2003) to be 35 and $4.38 \mathrm{~kg}$, respectively. The mean and SD of $B^{*}$ were calculated from Brossard et al. (2009), who used the data of Rivest (2004). In that study, the growth of a population of 192 pigs was analyzed and the Gompertz growth function was fitted separately for each animal. However, their analysis considered the total live weight of the pigs, instead of separating the protein and lipid growth. As a result, the value of $B$ estimated in that study is not directly comparable to the value used in our simulation. Therefore, a conversion was carried out as suggested by Emmans and Kyriazakis (1997): $B^{*}=B_{\mathrm{LW}}{ }^{*}\left(\operatorname{Pr}_{\mathrm{m}} / \mathrm{LW}_{\mathrm{m}}\right)^{0.27}$, where $B_{\mathrm{LW}}{ }^{*}$ is the scaled rate parameter for the live weight growth, calculated as described above from the $B$ value estimated by Brossard et al. (2009), and LW $\mathrm{m}$ is the live weight at maturity. Brossard et al. (2009) also provide the standard deviation for their estimate of $B$, and this was converted to correspond the SD of $B^{*}$ in our simulations following the calculations shown above, together with general error propagation rules. As a result, the values of the mean and SD of $B^{\star}$ were found to be a 0.0392 and 0.0078 day $^{-1}$. Finally, the mean and SD of $\operatorname{LPr}_{\mathrm{m}}$ were derived from Knap and Rauw (2008) to be 1.50 and $0.315 \mathrm{~kg} / \mathrm{kg}$, which were in turn adapted from Doeschl-Wilson et al. (2007). The mean $\operatorname{Pr}_{m}$ was $9 \%$ higher, while the $B^{*}$ and $\operatorname{LPr}_{m}$ were $4 \%$ and $8 \%$ lower, respectively, from those proposed by Wellock et al. (2004), which were based on the genetic line of van Lunen (1994). The changes in these values are consistent with genetic changes that have taken place in pig genotypes over a period of 10 years.

The model concentrated only on variation in the growth parameters, $B^{*}, \operatorname{Pr}_{m}$ and $\mathrm{LPr}_{\mathrm{m}}$. By varying the values of these parameters, it was possible to use the model to describe the actual phenotype variation in pig performance, including both growth and maintenance requirements. For simplicity, the model assumed a constant absorption coefficient for $P$ and a constant net efficiency of absorbed $P$ utilization across pigs, in accordance with Kyriazakis (2011). Even under the best growing conditions, there is likely to be variation in initial state between pigs at the start of a growing period (Wellock et al., 2004). Individual variation in BWO was generated from the assigned genotype mean $(\mu \mathrm{BW} 0, \mathrm{~kg})$ and $\mathrm{SD}(\sigma \mathrm{BW} 0, \mathrm{~kg})$ of $\mathrm{BW} 0$ using the simulated growth parameters of the individual to correlate BWO with potential growth, following the methodology by Wellock et al. (2003 and 2004).

A stochastic Monte Carlo simulation was used, created in Visual Basic Application in Microsoft Excel 2010, to simulate a pig population. For each simulated pig within the population, values for $B^{\star} i, \operatorname{Pr}_{\mathrm{m}} i$ and $\mathrm{LPr}_{\mathrm{m}} i$ were drawn at random from uncorrelated normal distributions for each of the growth parameter using their mean and SD values. These values were subsequently used to generate $\mathrm{BWO}_{\mathrm{i}}$. In Monte Carlo simulations, the number of simulations used is a compromise between the accuracy of the output (e.g. the estimate of the mean value) and the requirements of computing power. As the standard error of the output is directly dependent on the size of the sample, increasing the number of model runs will automatically improve the accuracy. However, in practice, Monte Carlo runs, especially with a complex simulation model, are time consuming, and this often determines the upper limit for the simulations to be used. In this study 500 runs (500 individuals) were used, since this was considered to be sufficient because the standard errors for the predicted mean values were $<0.5 \%$.

\section{Feeding strategies}

Phase feeding. Three feed sequence plans were investigated; feeding one, two or three different digP diets over the course of 30 to $120 \mathrm{~kg}$ average BW. Feeds in all simulations were identical in net energy $(9.68 \mathrm{MJ} / \mathrm{kg}), \mathrm{CP}(17.25 \%)$ and lysine $(1.11 \%)$. The pigs were offered ad libitum access to the diet. The simulated baseline diet, currently in use by the UK pig industry (Kyriazakis et al., 2013), had a chemical composition of $5.19 \mathrm{~g}$ total $\mathrm{Ca}$ and $4.29 \mathrm{~g}$ total P/kg. The dietary total $\mathrm{P}$ consisted of $2.47 \mathrm{~g}$ phytate (oP) and $1.82 \mathrm{~g}$ non-phytate $\mathrm{P}$ (NPP)/kg feed, and total digP was $2.67 \mathrm{~g} / \mathrm{kg}$. The average daily digP requirements $(\mathrm{g} / \mathrm{kg}$ feed) of the population were responsible for the changes seen in Table 1 in the digP and total Ca content of the feed $(\mathrm{g} / \mathrm{kg}$ feed) used. Within each phase of a feed sequence plan, the digP requirements (as $\mathrm{g} / \mathrm{kg}$ feed) of the population declined and so did the digP supplied. The feed changed when the average BW of the population reached the end of each phase (sequence plan). 
Table 1 The digestible $P(\mathrm{~g} / \mathrm{kg})$ contents of the feeds offered to the pigs during each of the feeding phases of a feeding sequence plan: one, two or three phases over the BW range 30 to $120 \mathrm{~kg}$

\begin{tabular}{|c|c|c|c|c|}
\hline \multirow[b]{2}{*}{ Feed sequence plan } & \multicolumn{2}{|c|}{ BW target $(\mathrm{kg})$} & \multicolumn{2}{|c|}{ Digestible P (g/kg feed) } \\
\hline & $1 / 2$ target & $1 / 3$ target & $1 / 2$ target & $1 / 3$ target \\
\hline \multicolumn{5}{|l|}{ One phase } \\
\hline 30 to $120 \mathrm{~kg} \mathrm{BW}^{1}$ & 75 & 60 & 2.28 & 2.50 \\
\hline \multicolumn{5}{|l|}{ Two phases } \\
\hline 30 to $74 \mathrm{~kg} \mathrm{BW}{ }^{1}$ & 52 & 45 & 2.62 & 2.76 \\
\hline 75 to $120 \mathrm{~kg} \mathrm{BW}{ }^{2}$ & 97.5 & 90 & 2.02 & 2.10 \\
\hline \multicolumn{5}{|l|}{ Three phases } \\
\hline 30 to $60 \mathrm{~kg} \mathrm{BW}^{1}$ & 45 & 40 & 2.76 & 2.84 \\
\hline 61 to $90 \mathrm{~kg} \mathrm{BW}^{3}$ & 75 & 70 & 2.28 & 2.34 \\
\hline 91 to $120 \mathrm{~kg} \mathrm{BW}{ }^{2}$ & 105 & 100 & 1.94 & 2.00 \\
\hline
\end{tabular}

$\mathrm{P}=$ phosphorus; $\mathrm{OP}=$ phytate; $\mathrm{NPP}=$ non-phytate phosphorus; $\mathrm{Ca}=$ calcium.

The supply of dietary digestible $P(\mathrm{dP} ; \mathrm{g} / \mathrm{kg})$ targeted the requirements of the average of the population at the mid-point $\mathrm{BW}(1 / 2$ target), or the mean BW during the first third of each feeding sequence plan (1/3 target).

${ }^{1}$ The $\mathrm{oP}: \mathrm{NPP}$ and $\mathrm{Ca}: \mathrm{dP}$ ratios used were $1.35: 1$ and $1.92: 1$, respectively, and derived from a typical 'grower' UK commercial diet.

${ }^{2}$ The $\mathrm{OP}: \mathrm{NPP}$ and $\mathrm{Ca}: \mathrm{dP}$ ratios used were $1.52: 1$ and $2.50: 1$, respectively, and derived from a typical 'finisher' UK commercial diet.

${ }^{3}$ The oP: NPP and $\mathrm{Ca}: \mathrm{dP}$ ratios used were $1.45: 1$ and $2.21: 1$, respectively, the intermidiate between the grower and finisher diets.

When the digP feeding regime changed, the oP: NPP and Ca: digP ratios also changed (Table 1 ). The dietary exogenous phytase supplementation (Escherichia coli) was constant through-out all phase feeding strategies, at 750 FTU/kg. The changes in the digP and total Ca content of the feed were achieved by changing the amount of supplemented inorganic $P$ and supplemented limestone, respectively.

The stochastic model determined the daily digP requirements for each individual in the population, based on their genotype, which were then averaged. The study examined the effect of supplying dietary digP to meet the digP requirements of the average of the population at either the mid-point BW (1/2 target) or the average BW of the first third of each feeding sequence (1/3 target; Table 1). The $1 / 2$ target strategy is often practiced by the industry, whereas the $1 / 3$ target strategy is also practiced but to a lesser extent (Simpson and de Lange, 2004). As the number of phases increases the differences between the digP supplied by the $1 / 2$ and $1 / 3$ target plan diminished.

Sorting according to $B W$. The effect of sorting the lightest $10 \%, 20 \%$ and $30 \%$ BW of the pig population and feeding them a separate digP content feed from the rest of the population on P excreted was investigated. The sorting of the population took place by arranging all pigs in the population, from the lightest to the heaviest, in accordance to the $\mathrm{BWO}_{\mathrm{i}}$, at an average $30 \mathrm{~kg} \mathrm{BW}$. The sorted and 'rest' population were fed different feeds in terms of digP and total Ca during the BW intervals of 30 to 74 and 75 to $120 \mathrm{~kg}$. The lightest $10 \%, 20 \%$ and $30 \%$ BW had an extra feed sequence plan, until this group reached the average $30 \mathrm{~kg}$ BW (Table 2). Therefore, the sorted pigs were effectively offered three feeding phases, while the 'rest' had two feeding phases. There was also a control simulation, in which no sorting of the population took place.
For each group of pigs, the dietary digP supplied ( $\mathrm{g} / \mathrm{kg}$ diet) met the average digP requirements half way through each stage (half-way target), that is, 52 and $97.5 \mathrm{~kg} \mathrm{BW}$ for the grower (30 to $74 \mathrm{~kg} \mathrm{BW}$ ) and finisher ( 75 to $120 \mathrm{~kg} \mathrm{BW}$ ) stages, respectively. The sorted pigs were fed a higher digP compared with the 'rest' of the population in order to meet their higher digP requirements (Table 2). The time taken for each sub-population to reach the target BW was recorded. The baseline feed fed to each group was the same with the phase feeding regime, having the same composition and nutritional value, with the only exception being its $P$ and $C a$ level (see above). The higher digP requirements of the pigs $<30 \mathrm{~kg} \mathrm{BW}$ required the supplementation of the feed with monocalcium phosphate and limestone to achieve the $\operatorname{digP}$ and total $\mathrm{Ca}$ contents (Table 2). The rules used for the change in the digP and $\mathrm{Ca}$ contents of the feeds offered to the remaining of the population were the same as for phase feeding.

\section{Simulation outputs}

From the generated simulated populations, which were fed according to the strategies described above, the following outputs were calculated: (1) the cumulative $P$ excretion as total, soluble and insoluble $P(\mathrm{~kg}) ;(2)$ the population performance (mean and CV) in terms of BW gain (kg/day), $\mathrm{Pr}$ and $P$ retained ( $g /$ day) and food conversion ratio; (3) the percentage of the population that had their digP requirements met throughout the BW period 30 to $120 \mathrm{~kg}$ of the population; and (4) the percentage of the population that were supplied $<85 \%$ of their requirements at any one stage of their growth, in order to identify the level of $P$ underfeeding that happened within the population.

The cumulative soluble and insoluble $P$ excretion for each pig was calculated by adding the daily soluble and insoluble $P$ excreted, respectively, to derive the total amount of soluble and insoluble P excreted to the environment from 30 to $120 \mathrm{~kg} \mathrm{BW}$ 
Symeou, Leinonen and Kyriazakis

Table 2 The digestible $P(\mathrm{~g} / \mathrm{kg}$ ) contents of the diets offered to pigs during each of the feeding phases of a 'sorting plan': the pigs were either treated as a single population (no sorting), or the lightest 10\%, 20\% and $30 \%$ of the population were fed on a higher digestible $P$ in comparison with the remaining population

\begin{tabular}{lccc}
\hline \hline & \multicolumn{3}{c}{ Digestible P (g/kg feed) } \\
\cline { 2 - 4 } Sorting plan & $<30 \mathrm{~kg} \mathrm{BW}^{3}$ & 30 to $74 \mathrm{~kg} \mathrm{BW}$ & 75 to $120 \mathrm{~kg} \mathrm{BW}^{2}$ \\
\hline No sorting & - & 2.62 & 2.02 \\
$\quad 10 \%$ sorting & 2.99 & 2.77 & 2.12 \\
$10 \%$ lightest & - & 2.60 & 2.00 \\
$\quad$ Remaining population & 2.99 & 2.73 & 2.11 \\
$20 \%$ sorting & - & 2.57 & 1.98 \\
$20 \%$ lightest & & & 2.09 \\
Remaining population & - & 2.71 & 1.98 \\
$30 \%$ sorting & - & 2.56 & \\
$30 \%$ lightest & Remaining population &
\end{tabular}

$\mathrm{P}=$ phosphorus; $\mathrm{OP}=$ phytate; $\mathrm{NPP}=$ non-phytate phosphorus; $\mathrm{Ca}=$ calcium.

The supply of dietary digestible $\mathrm{P}(\mathrm{dP} ; \mathrm{g} / \mathrm{kg})$ was determined in order to meet the average digestible $\mathrm{P}$ requirements of the sorted and remaining population at the mid-point $\mathrm{BW}$ of each feeding phase.

${ }^{1}$ The $\mathrm{OP}: \mathrm{NPP}$ and $\mathrm{Ca}: \mathrm{dP}$ ratios used were $1.35: 1$ and $1.92: 1$, respectively, and derived from a typical 'grower' UK commercial diet.

${ }^{2}$ The $\mathrm{OP}: \mathrm{NPP}$ and $\mathrm{Ca}: \mathrm{dP}$ ratios used were $1.52: 1$ and $2.50: 1$, respectively, and derived from a typical 'finisher' UK commercial diet.

${ }^{3}$ The $\mathrm{OP}: \mathrm{NPP}$ and $\mathrm{Ca}: \mathrm{dP}$ ratios used were $0.61: 1$ and $1.80: 1$, respectively, and derived from a typical 'weaner' UK commercial diet.

for each pig, and subsequently added to calculate the soluble and insoluble P excreted for the whole population.

In order to quantify the percentage of population supplied $<85 \%$ of their requirements, it was first necessary to identify the level of underfeeding or overfeeding of digP for each pig for each day, compared with its daily requirements. These data were used to count the number of pigs that were supplied $<85 \%$ of their requirements for each day in a population. Calculating the percentage population supplied with $<85 \%$ of their requirements was in accordance with NRC (2012), who states that if pigs are undersupplied with digP by $>15 \%$ of their requirements, this will negatively affect their growth.

\section{Results}

Comparison with experimental results

The deterministic model had been validated previously by comparing its outputs with the treatment mean values of experimental data found in literature (Symeou et al., 2014b). To investigate the output of the stochastic model, the variation in two output variables of interest, $P$ retention and $P$ excretion was compared with the reported data of within-treatment variation obtained from the same literature. In this study, the CV of P retention varied between $8 \%$ and $15 \%$ depending on the simulated feeding strategy. The experimental data used for model evaluation in Symeou et al. (2014b) show higher CV values than predicted by the model, ranging between $22 \%$ and $41 \%$. The CV for the model output of P excretion was about $10 \%$ (data not shown), while the CV values from the literature varied widely between $5 \%$ and $58 \%$, with a typical value being around $20 \%$. It should be noted that the lowest CV in P excretion (5\%), observed by Trujillo et al. (2010), was a result of extremely high absolute levels of $\mathrm{P}$ intake and excretion (as a result of the specific feeds used) and therefore does not indicate any lower absolute variation of $\mathrm{P}$ excretion compared with other studies.

\section{Phase feeding}

As the number of feed phases increased over the BW period 30 to $120 \mathrm{~kg}$, the amount of cumulative $P$ excreted by the population of pigs decreased (Table 3). There was an average decrease of $7.50 \%$ and $9.29 \%$ in total cumulative P excreted, when the feeding phases increased from one to two and from one to three, respectively. Similarly the largest decrease in soluble and insoluble cumulative P excreted was seen when the feeding phases increased from one to two. The cumulative $P$ excreted was lower when the $1 / 2$ target, as opposed to the $1 / 3$ target was used; this was consistent across all feed sequence plans. When the $1 / 2$ target feeding regime was used, $13.9 \%, 8.24 \%$ and $3.84 \%$ less soluble $P$ was excreted, in comparison with the $1 / 3$ target feeding regime, for each of the phase feeding sequences (1, 2 and 3 phase feeding, respectively). Across all phase feeding plans used, soluble $P$ contributed $\sim 75 \%$ of the total P excreted. The standard errors of the estimated mean values for the total $P$ excreted were relatively low $(\sim 1 \%)$ for all phase feeding scenarios, which indicates that these estimates reliably represent the true means of the population.

Increasing the number of feeding phases resulted in a higher percentage of the population meeting their digP requirements during the average BW period 30 to $60 \mathrm{~kg}$ (Figure 1). The converse was the case during the finishing stage of 90 to $120 \mathrm{~kg}$, where a lower percentage of population met their $P$ requirements when the feeding phases increased. The use of the 1 phase feeding resulted in the highest percentage of the population being undersupplied with digP (Figure 2). Similarly the use of the $1 / 2$ target feeding regime resulted in a higher percentage of pigs being 
Table 3 The effect of phase feeding (one, two or three phases) on the cumulative total, soluble and insoluble $P$ excreted ( $\mathrm{kg}$ ) from 30 to $120 \mathrm{~kg}$ average $B W$, for a population of 500 pigs, when the supply of dietary digestible $P$ targeted the digestible $P$ requirements of the average of the population at the mid-point BW (1/2 target), or the mean BW of the first third of each feeding sequence plan (1/3 target)

\begin{tabular}{|c|c|c|c|c|c|c|c|c|c|}
\hline \multirow[b]{3}{*}{ Phase feeding } & \multicolumn{9}{|c|}{ Cumulative P excreted $(\mathrm{kg})$} \\
\hline & \multicolumn{3}{|c|}{ Total } & \multicolumn{3}{|c|}{ Insoluble } & \multicolumn{3}{|c|}{ Soluble } \\
\hline & $1 / 2$ target & $1 / 3$ target & Mean & $1 / 2$ target & $1 / 3$ target & Mean & $1 / 2$ target & $1 / 3$ target & Mean \\
\hline 1 & 261 & 298 & 280 & 69.1 & 75.6 & 72.4 & 192 & 223 & 207 \\
\hline 2 & 250 & 268 & 259 & 67.7 & 70.9 & 69.3 & 182 & 197 & 190 \\
\hline 3 & 249 & 259 & 254 & 67.3 & 69.9 & 68.6 & 182 & 189 & 186 \\
\hline
\end{tabular}

$\mathrm{P}=$ phosphorus.

undersupplied with digP, rather than when the $1 / 3$ target feeding regime was used.

The majority of the population $(>50 \%)$ were supplied $<85 \%$ of their digP requirements from 30 to $48 \mathrm{~kg}$ and from 30 to $36 \mathrm{~kg}$ average population BW, through the use of the $1 / 2$ target and $1 / 3$ target feeding regimes, respectively, when the 1 phase feeding was used. When feeding a 2 and 3 phase sequence, the percentage of the population that was underfed never exceeded $50 \%$ at any stage of the population growth (maximum of $\mathrm{P}$ underfed pigs was $27 \%$ and $17 \%$, respectively, when the 2 and 3 phase feeding plans were used).

There was an increase in $A D G, \operatorname{Pr}$ and $P$ retained ( $g /$ day), and a decrease in the food conversion ratio (FCR) when the number of feeding phases increased (Table 4). In addition, the $\mathrm{CV}$ decreased with increasing the number of phases for all the above performance variables. Pigs on the $1 / 3$ target performed better than on the $1 / 2$ target for all investigated performance variables, irrespective of the number of feeding phases. The greatest difference in ADG between the $1 / 3$ and $1 / 2$ target feeding regime, was $0.60 \%$ during 1 phase feeding. In addition, there was a lower CV for the population performance variables, when the $1 / 3$ target was used as opposed to the $1 / 2$ target. Nevertheless, the difference in the population performance between the $1 / 2$ and $1 / 3$ target decreased while the number of the feeding phases increased.

\section{Sorting according to $B W$}

Sorting pigs into 'light' and 'remaining' groups, increasing the size of the light group and feeding each group in accordance to their average digP requirements resulted in a decrease in the cumulative $\mathrm{P}$ excreted by the population as a whole (Table 5). There was a $1.32 \%, 1.92 \%$ and $3.04 \%$ reduction in the cumulative total $\mathrm{P}$ excreted by the population as a whole, when $10 \%, 20 \%$ and $30 \%$ of the population were sorted, in comparison with the equivalent group in the population that was not sorted. The cumulative total $\mathrm{P}$ excreted by the sorted lightest $10 \%, 20 \%$ and $30 \%$ of the population increased by $49 \%, 43 \%$ and $40 \%$, respectively, compared with the equivalent group of the population when not sorted. The reverse was the case for the remaining of the population, as 'remaining' pigs excreted $5.17 \%, 9.91 \%$ and
$16.2 \%$ less total $P$, respectively, compared with the equivalent group of the population that was not sorted. Across all sorting regimes used, soluble $\mathrm{P}$ contributed $\sim 75 \%$ of the total $P$ excreted. The standard errors of the estimated mean values for the total P excreted were relatively low $(\sim 1 \%)$ for all sorting scenarios, which indicates that these estimates reliably represent the true means of the population.

As expected, a larger percentage of the 'light' pigs met their $P$ requirements at any stage of their growth compared with the equivalent group of the population that were not sorted (Figure 3). The largest difference between sorted and not sorted light pigs in the percentage of pigs that met their requirements, was between 60 to $75 \mathrm{~kg}$ BW. The 'remaining' population had a much smaller difference between sorted and not sorted pigs in the percentage of pigs that met their requirements, in comparison with the 'light' group. The percentage of population that met their individual digP requirements was increasing with increasing $B W$ of the average population. The only exception to this trend was at the initial stages of growth for the 'light' group, which was relatively constant.

A smaller percentage of 'light' pigs were supplied $<85 \%$ of their digP requirements at any stage of growth, compared with the equivalent group of the population that were not sorted (Figure 4). The reverse was the case for the 'remaining' of the population; a larger percentage of the 'remaining' pigs were supplied $<85 \%$ of their digP at any stage of their growth, compared with the equivalent group of the population that were not sorted. Nevertheless, the difference between the sorted and not sorted regimes was higher for the light group compared with the remaining group.

Increasing the size of the 'light' group resulted in an increase in their average initial $\mathrm{BW}$ and a decrease in the time needed to reach the target BW of $30 \mathrm{~kg}$ (Table 6). The average initial BW of the lightest $10 \%, 20 \%$ and $30 \%$ of the sorted population was $5.5,4.2$ and $3.3 \mathrm{~kg}$ lighter than that of the unsorted population and needed 114, 111 and 109 days to reach the average BW of $120 \mathrm{~kg}$. For the remaining $90 \%, 80 \%$ and $70 \%$ of the population, their average initial BW was $0.9,1.3$ and $1.7 \mathrm{~kg}$ heavier and needed 88,86 and 84 days to reach the average BW of $120 \mathrm{~kg}$, respectively. The CV of the 'remaining' group was 

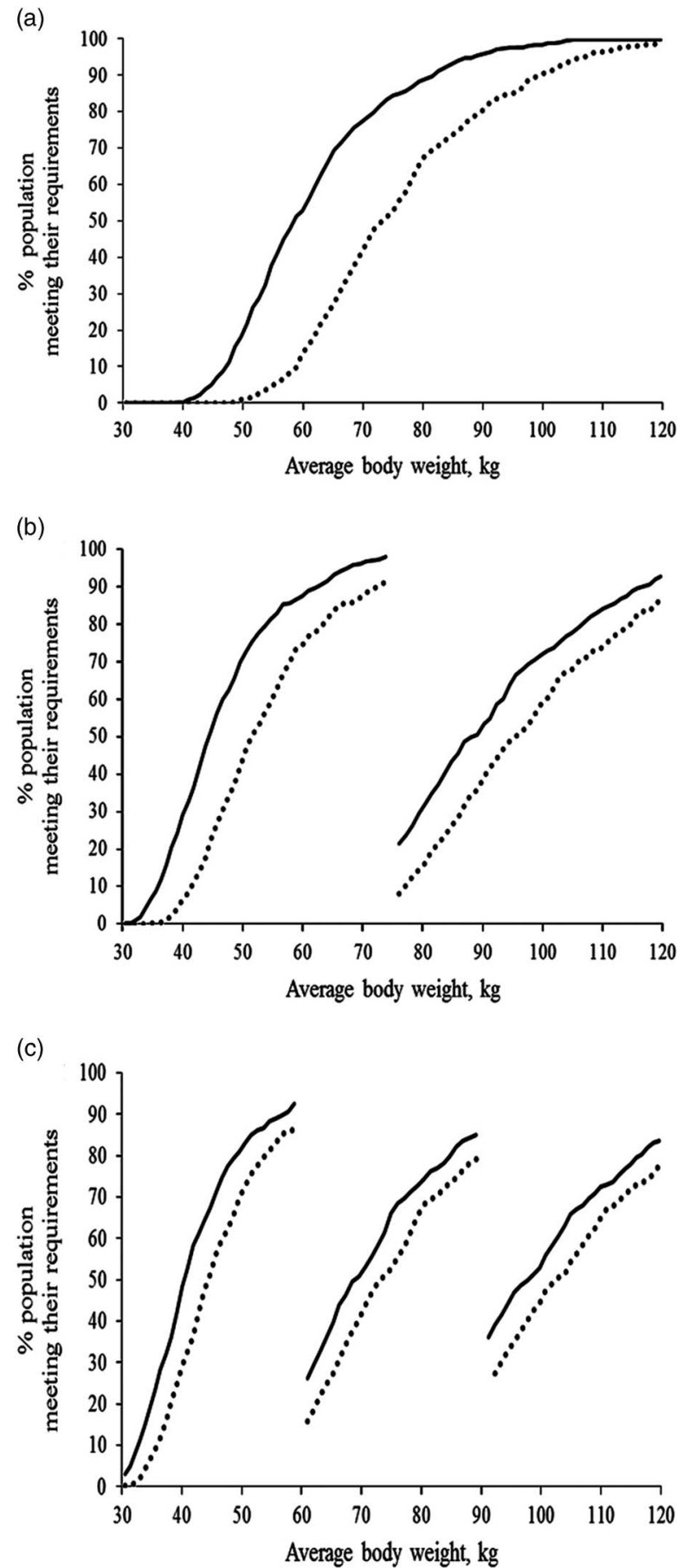

Figure 1 Percentage of the population whose digestible $P$ requirements were met over the average BW range 30 to $120 \mathrm{~kg}$, during a feeding sequence plan: (a) one phase; (b) two phases or; (c) three phases over the BW range 30 to $120 \mathrm{~kg}$. The supply of dietary digestible $P$ targeted the digestible $P$ requirements of the average of the population at the mid-point BW (...), or the mean BW of the first third $(\square)$ of each feeding sequence plan.

smaller than for the 'light' group. In addition, the smaller the size of each group, the smaller the $\mathrm{CV}$.

The greatest effect of sorting on all the performance variables was when the lightest $30 \%$ of the population was sorted (Table 7). The performance of the sorted 'light' group increased compared with the equivalent group of the
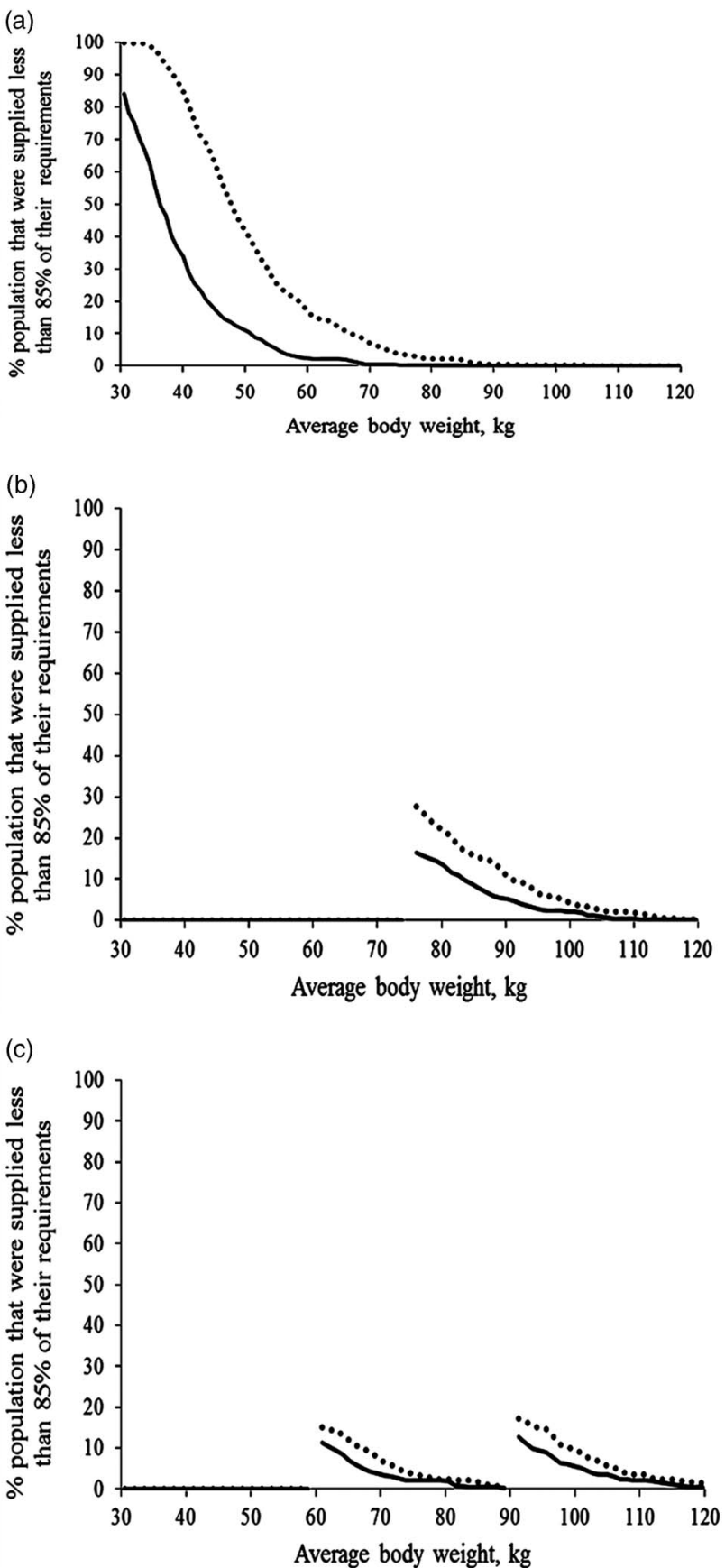

Figure 2 Percentage of population supplied with $<85 \%$ of their digestible $P$ requirements during a feeding sequence plan: (a) one phase; (b) two phases or; (c) three phases over the average BW range 30 to $120 \mathrm{~kg}$. The supply of dietary digestible $P$ targeted the digestible $P$ requirements of the average of the population at the mid-point BW $(\cdots)$, or the mean BW of the first third $(\square)$ of each feeding sequence plan.

population when not sorted. The converse was the case for the 'remaining' group, as the performance decreased, compared with the equivalent group of the population that were not sorted. The CV of all population performance variables decreased with increasing the size of the 'light' group. The CV of the ADG for the sorted pigs increased by sorting, while the $\mathrm{CV}$ of the protein and $\mathrm{P}$ retained decreased in comparison with the equivalent group of the population that were not sorted. 
Table 4 The effect of phase feeding (one, two or three phases) on the performance of a population of pigs from 30 to $120 \mathrm{~kg}$ in terms of: (1) average daily gain (ADG) (kg/day); (2) protein ( $\mathrm{Pr}$ ) retained (g/day); (3) phosphorus (P) retained (g/day) and (4) food conversion ratio

\begin{tabular}{|c|c|c|c|c|c|c|c|c|c|}
\hline \multirow[b]{2}{*}{ Phase Feeding } & \multirow[b]{2}{*}{ BW target $(\mathrm{kg})$} & \multicolumn{2}{|c|}{ ADG (kg/day) } & \multicolumn{2}{|c|}{ Pr retained (g/day) } & \multicolumn{2}{|c|}{$\mathrm{P}$ retained (g/day) } & \multicolumn{2}{|c|}{ Food conversion ratio } \\
\hline & & Mean & CV & Mean & CV & Mean & $\mathrm{CV}$ & Mean & CV \\
\hline \multirow[t]{2}{*}{1} & $1 / 2$ & 1.006 & 0.1153 & 173 & 0.1345 & 5.44 & 0.1479 & 3.02 & 0.177 \\
\hline & $1 / 3$ & 1.012 & 0.0974 & 175 & 0.1041 & 5.64 & 0.1260 & 3.00 & 0.150 \\
\hline \multirow[t]{2}{*}{2} & $1 / 2$ & 1.024 & 0.0978 & 177 & 0.1005 & 5.60 & 0.1047 & 2.97 & 0.150 \\
\hline & $1 / 3$ & 1.025 & 0.0911 & 180 & 0.0926 & 5.72 & 0.0874 & 2.96 & 0.140 \\
\hline \multirow[t]{2}{*}{3} & $1 / 2$ & 1.027 & 0.0929 & 180 & 0.0960 & 5.65 & 0.0909 & 2.96 & 0.143 \\
\hline & $1 / 3$ & 1.029 & 0.0901 & 182 & 0.0895 & 5.75 & 0.0809 & 2.95 & 0.140 \\
\hline
\end{tabular}

The supply of dietary digestible P targeted the digestible P requirements of the average of the population at the mid-point BW (1/2 target), or the mean BW of the first third of each feeding sequence plan (1/3 target).

Table 5 The total, soluble and insoluble cumulative $P$ excreted by a population of 500 pigs treated according to a 'sorting plan': the pigs were either treated as a single population, (no sorting), or the lightest $10 \%, 20 \%$ and $30 \%$ of the population were fed a higher digestible P in comparison with the remaining population

\begin{tabular}{|c|c|c|c|c|c|c|}
\hline \multirow[b]{3}{*}{ Sorting plan } & \multicolumn{6}{|c|}{ Cumulative P excreted $(\mathrm{kg})$} \\
\hline & \multicolumn{2}{|c|}{ Total } & \multicolumn{2}{|c|}{ Insoluble } & \multicolumn{2}{|c|}{ Soluble } \\
\hline & No sorting & Sorting & No sorting & Sorting & No sorting & Sorting \\
\hline \multicolumn{7}{|l|}{$10 \%$ sorting } \\
\hline $10 \%$ lightest & 17.6 & 26.3 & 5.00 & 7.10 & 12.6 & 19.3 \\
\hline Remaining population & 232 & 220 & 62.5 & 58.8 & 170 & 161 \\
\hline Total & 250 & 246 & 67.5 & 65.9 & 183 & 180 \\
\hline \multicolumn{7}{|l|}{$20 \%$ sorting } \\
\hline $20 \%$ lightest & 38.0 & 54.2 & 10.8 & 14.6 & 27.2 & 39.7 \\
\hline Remaining population & 212 & 191 & 56.7 & 52.3 & 155 & 139 \\
\hline Total & 250 & 245 & 67.5 & 66.9 & 182 & 179 \\
\hline \multicolumn{7}{|l|}{$30 \%$ sorting } \\
\hline $30 \%$ lightest & 59.0 & 82.4 & 16.7 & 22.0 & 42.3 & 60.3 \\
\hline Remaining population & 191 & 160 & 50.8 & 39.8 & 140 & 120 \\
\hline Total & 250 & 242 & 67.5 & 61.8 & 182 & 180 \\
\hline
\end{tabular}

$\mathrm{P}=$ phosphorus.

The supply of dietary digestible $\mathrm{P}(\mathrm{g} / \mathrm{kg})$ was determined to meet the average digestible P requirements of the sorted and remaining population at the mid-point BW of each feeding phase.

\section{Discussion}

The developed stochastic model was based on a deterministic mechanistic model previously evaluated using independent data (Symeou et al., 2014a and 2014b). This provides some confidence in its outputs, provided that the sources of variation in model outputs have been estimated accurately. The data used to evaluate the deterministic model was also used here to compare the variation in the stochastic model outputs with the variation observed in published experiments. The stochastic model generally underestimated the CV associated with $\mathrm{P}$ retention and excretion. This is likely to reflect unaccounted sources of variation between real animals. This difference between the actual and modeled populations is expected, as the aim of this study was to consider only the variation in the animal protein and lipid growth, thus leaving other factors potentially affecting the variation in $\mathrm{P}$ retention outside the analysis.
Although feed composition changed during the course of the simulation according to the investigated feeding strategies, the composition of the feed at any particular point in time was not subject to stochastic variation. This is again a simplification, as feed composition may vary randomly, due to variation in nutrient composition of the ingredients that compose a feed (Kim et al., 2002) or uncertainty introduced by feed processing or mixing (Groesbeck et al., 2007). Introducing uncertainty in feed composition and environmental features is a long neglected issue in nutrition and metabolism models, and represents our next challenge in model development.

\section{Phase feeding}

Phase feeding is the most studied feeding strategy, when aiming to decrease nutrient excretion (Lenis, 1989; Coppoolse et al., 1990; Henry and Dourmad, 1993; Han et al., 1998; Lee et al., 2000; Brossard et al., 2009; 
(a)

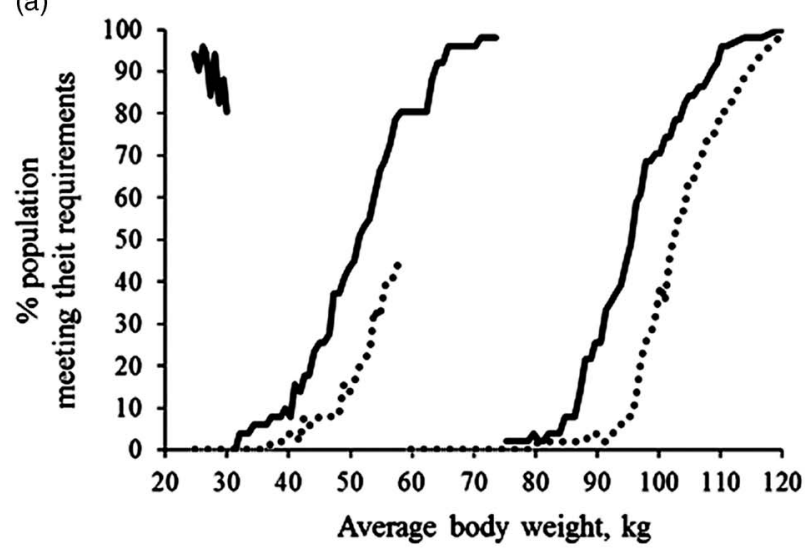

(c)

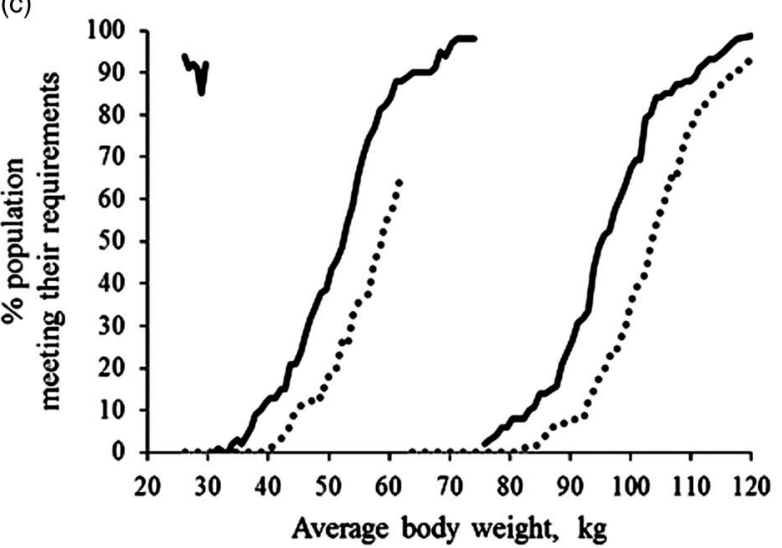

(e)

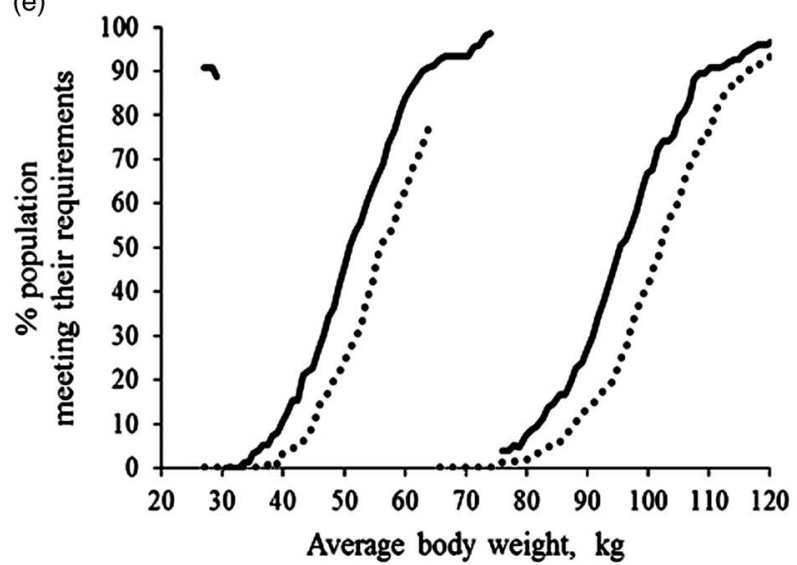

(b)

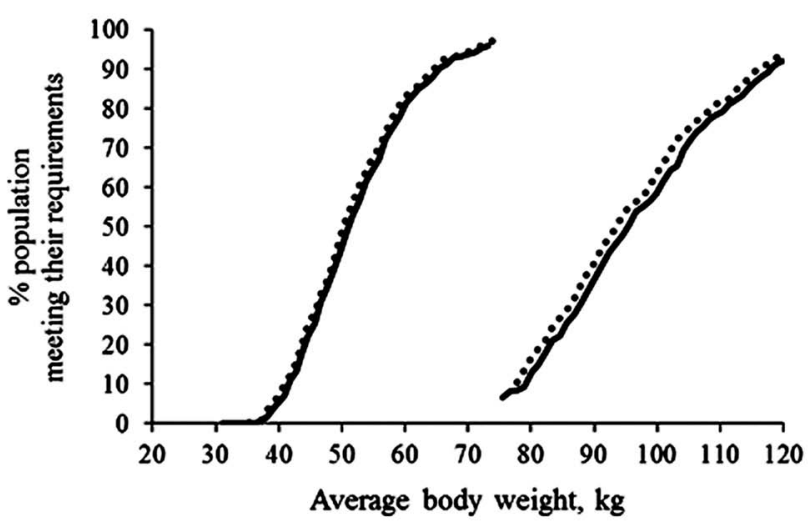

(d)

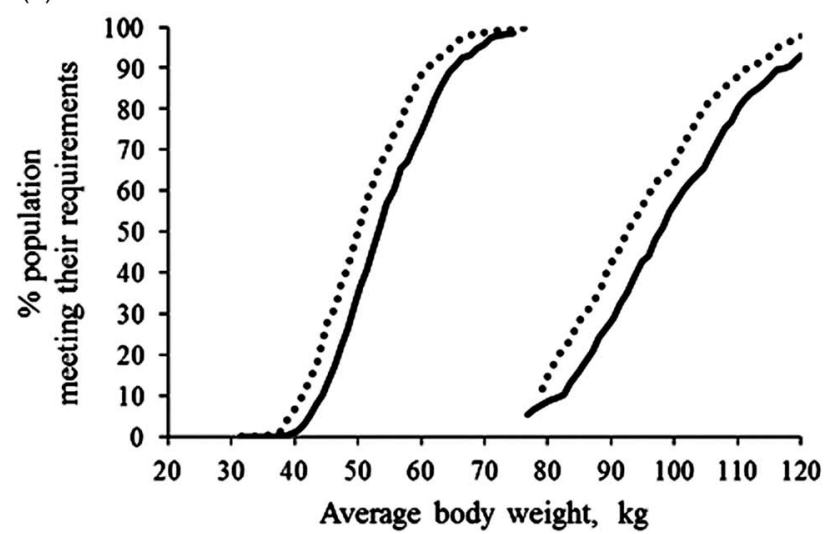

(f)

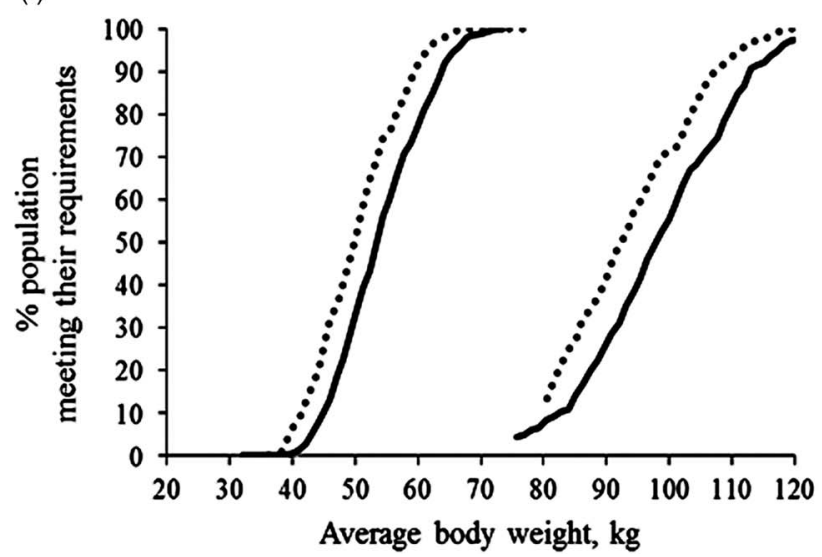

Figure 3 Percentage of the population whose digestible P requirements were met over the average BW range 30 to $120 \mathrm{~kg}$ during a 'sorting' plan: the lightest $10 \%$ (a), $20 \%$ (c), $30 \%$ (e) of pigs in the population were fed a higher digestible $\mathrm{P}$, in comparison with the remaining (b) $90 \%$, (d) $80 \%$ and (f) $70 \%$ population. Comparisons between light and remaining pigs are made within rows (e.g. (a) $v$. (b)) whereas comparisons within a class of pigs are made within columns (e.g. lightest pigs: (a), (c) and (e)); comparisons are also made between these subpopulations when they were sorted ( $\square$ ) or not ( $\cdots$ ) (i.e. treated as a single population).

Pomar et al., 2011). In theory, the content of the feed in the nutrient whose excretion is aimed to be minimized should change as frequently as possible. There are of course limits on how often this can be achieved without disruption in farm practices, although with the advances of livestock precision farming, the delivery of mixtures between two (basal) feeds to deliver the appropriate amount nutrient in the feed at group or individual level may be possible (Pomar et al., 2009).
Increasing the number of feed changes (feeding phases) resulted in the expected decreases in $\mathrm{P}$ excretion, in total, insoluble and soluble $P$ forms. The decreases were more dramatic when the feeding regime changed from one to two phases, rather than from two to three phases. It is likely that the reductions in $\mathrm{P}$ excretion follow the law of diminishing returns when the number of feeding phases increases. $P$ excretion was higher using the $1 / 3$ target, as opposed 
(a)

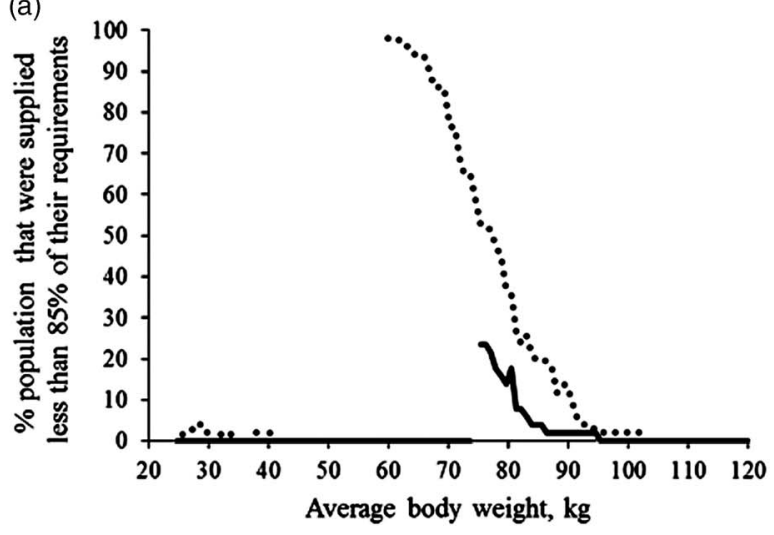

(c)

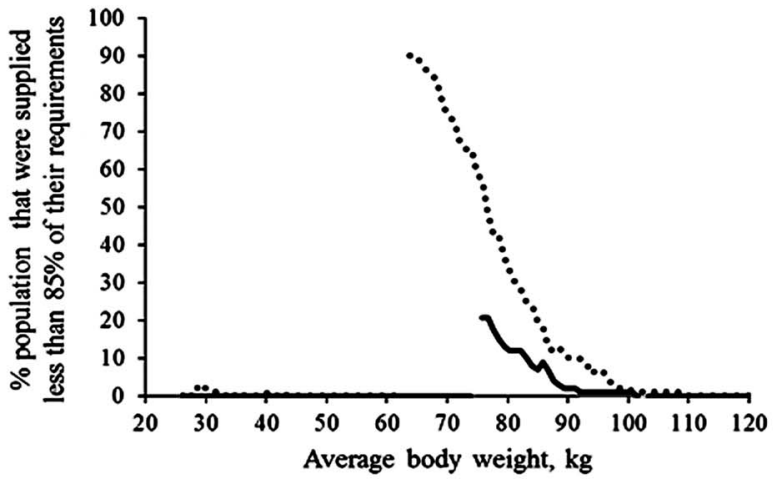

(e)

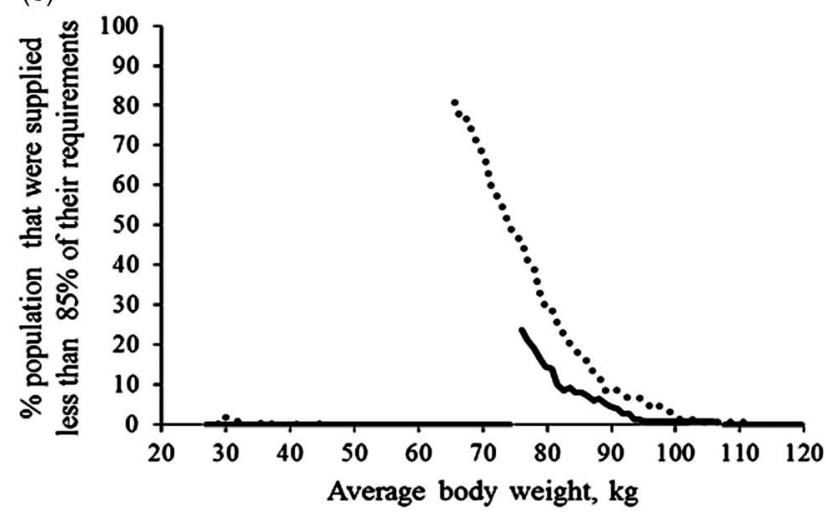

(b)

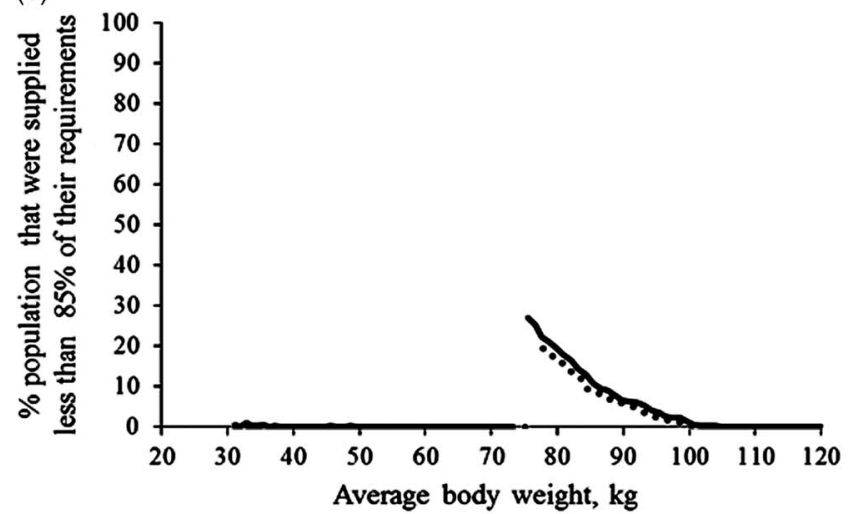

(d)

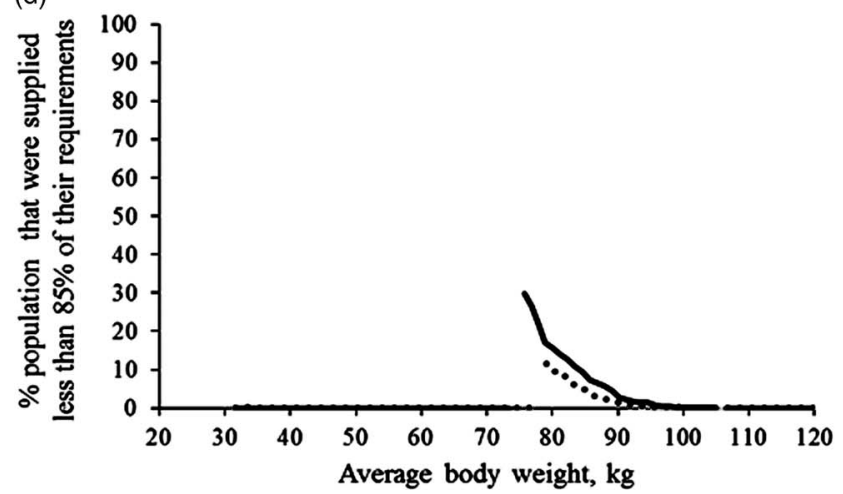

(f)

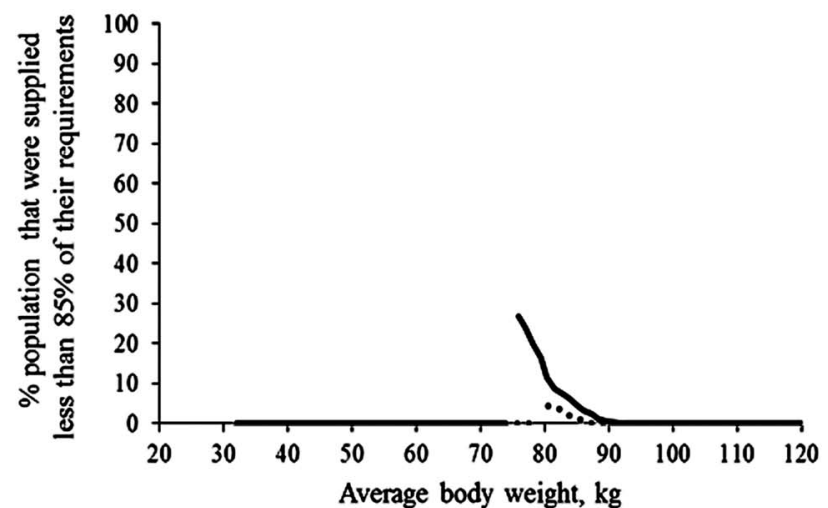

Figure 4 Percentage of population supplied with $<85 \%$ of their digestible P requirements over the average BW range 30 to $120 \mathrm{~kg}$ during a 'sorting' plan: the lightest $10 \%$ (a), $20 \%$ (c), $30 \%$ (e) of the pigs in the population were fed a higher digestible $P$, in comparison with the remaining (b) $90 \%$, (d) $80 \%$ and (f) $70 \%$ pigs in the population. Comparisons between light and remaining pigs are made within rows (e.g. (a) $v$. (b)) whereas comparisons within a class of pigs are made within columns (e.g. lightest pigs: (a), (c) and (e)); comparisons are also made between these subpopulations when they were sorted $(\square)$ or not $(\cdots)$ (i.e. treated as a single population).

to $1 / 2$ target, and consequently the reductions in $\mathrm{P}$ excretion were higher in the former regime when the feed changes were more frequent. This is consistent with the simulation of Pomar et al. (2011) who found substantial reductions in P excretion through individual precision feeding as opposed to threephase feeding; the latter met the digP requirements of the average of the population at the start of each phase. These findings cannot be compared directly with literature; when phase feeding has been practiced experimentally both the $\mathrm{P}$ and $\mathrm{N}$ content of the feed has changed simultaneously
(Lenis, 1989; Coppoolse et al., 1990; Henry and Dourmad, 1993), and there is no direct correspondence between the feeds and animals used in the experiments and the simulation. Nevertheless, the former two studies have found a reduction of $6 \%$ in $P$ excretion by moving from one to two phases, which is comparable to the reductions achieved here when the same feeding regime applied (7\%). The trigger for changes in the feed composition of the different phases used in our simulations was weight, although time could also be used. It is unlikely that the conclusions 
Symeou, Leinonen and Kyriazakis

Table 6 The initial average BW and the time taken by pigs on each of the feeding phases of a 'sorting plan': the pigs were either treated as a single population (no sorting) or the lightest $10 \%, 20 \%$ and $30 \%$ of the population were fed on a higher digestible $P$, in comparison with the remaining of the population

\begin{tabular}{|c|c|c|c|c|c|c|c|c|c|}
\hline \multirow[b]{4}{*}{ Sorting Plan } & \multicolumn{9}{|c|}{ BW range $(\mathrm{kg})$} \\
\hline & \multicolumn{3}{|c|}{$<30$} & \multicolumn{3}{|c|}{$30-74$} & \multicolumn{3}{|c|}{$75-120$} \\
\hline & \multicolumn{2}{|c|}{ Start BW (kg) } & \multirow[b]{2}{*}{ Time taken (days) } & \multicolumn{2}{|c|}{ Start BW (kg) } & \multirow[b]{2}{*}{ Time taken (days) } & \multicolumn{2}{|c|}{ Start BW (kg) } & \multirow[b]{2}{*}{ Time taken (days) } \\
\hline & Mean & $\mathrm{CV}$ & & Mean & CV & & Mean & $\mathrm{CV}$ & \\
\hline No sorting & - & - & - & 30.3 & 0.0944 & 47 & 74.9 & 0.1576 & 43 \\
\hline \multicolumn{10}{|l|}{$10 \%$ sorting } \\
\hline $10 \%$ lightest & 24.8 & 0.0626 & 10 & 30.0 & 0.0738 & 55 & 74.5 & 0.1673 & 49 \\
\hline Remaining population & - & - & - & 31.2 & 0.0702 & 45 & 74.5 & 0.1376 & 43 \\
\hline \multicolumn{10}{|l|}{$20 \%$ sorting } \\
\hline $20 \%$ lightest & 26.1 & 0.0681 & 8 & 30.3 & 0.0759 & 52 & 74.9 & 0.1590 & 51 \\
\hline Remaining population & - & - & - & 31.6 & 0.0589 & 44 & 74.5 & 0.1303 & 42 \\
\hline \multicolumn{10}{|l|}{$30 \%$ sorting } \\
\hline $30 \%$ lightest & 27.0 & 0.0707 & 6 & 29.8 & 0.0772 & 51 & 75.1 & 0.1542 & 52 \\
\hline Remaining population & - & - & - & 32.0 & 0.0498 & 43 & 75.0 & 0.1208 & 41 \\
\hline
\end{tabular}

$P=$ phosphorus.

The supply of dietary digestible $P(\mathrm{~g} / \mathrm{kg}$ ) was determined in order to meet the average digestible $\mathrm{P}$ requirements of the sorted and remaining population at the mid-point BW of each feeding phase.

Table 7 The effect of a 'sorting' plan on the performance of a population of pigs from 30 to $120 \mathrm{~kg}$ in terms of: (1) average daily gain (ADG) ( $\mathrm{kg} /$ day); (2) protein (Pr) retained ( $g /$ day) and (3) phosphorus (P) retained

\begin{tabular}{|c|c|c|c|c|c|c|c|c|c|c|c|c|}
\hline \multirow[b]{3}{*}{ Sorting plan } & \multicolumn{4}{|c|}{ ADG (kg/day) } & \multicolumn{4}{|c|}{ Pr retained (g/day) } & \multicolumn{4}{|c|}{$\mathrm{P}$ retained (g/day) } \\
\hline & \multicolumn{2}{|c|}{ No sorting } & \multicolumn{2}{|c|}{ Sorting } & \multicolumn{2}{|c|}{ No sorting } & \multicolumn{2}{|c|}{ Sorting } & \multicolumn{2}{|c|}{ No sorting } & \multicolumn{2}{|c|}{ Sorting } \\
\hline & Mean & CV & Mean & CV & Mean & CV & Mean & CV & Mean & $\mathrm{CV}$ & Mean & $\mathrm{CV}$ \\
\hline \multicolumn{13}{|l|}{$10 \%$ Sorting } \\
\hline $10 \%$ lightest & 0.811 & 0.1012 & 0.819 & 0.1078 & 149 & 0.13 & 151 & 0.128 & 4.25 & 0.1192 & 4.65 & 0.117 \\
\hline Remaining population & 1.057 & 0.0937 & 1.054 & 0.0944 & 182 & 0.108 & 181 & 0.1074 & 5.72 & 0.1107 & 5.7 & 0.1092 \\
\hline \multicolumn{13}{|l|}{$20 \%$ Sorting } \\
\hline $20 \%$ lightest & 0.875 & 0.0997 & 0.879 & 0.1046 & 160 & 0.1258 & 161 & 0.1249 & 4.62 & 0.1186 & 4.95 & 0.1147 \\
\hline Remaining population & 1.072 & 0.0932 & 1.066 & 0.0952 & 183 & 0.1063 & 182 & 0.1057 & 5.81 & 0.1099 & 5.77 & 0.109 \\
\hline \multicolumn{13}{|l|}{$30 \%$ Sorting } \\
\hline $30 \%$ lightest & 0.897 & 0.0987 & 0.900 & 0.104 & 163 & 0.1236 & 164 & 0.1168 & 4.77 & 0.1184 & 5.04 & 0.1124 \\
\hline Remaining population & 1.091 & 0.0922 & 1.082 & 0.0993 & 185 & 0.1046 & 184 & 0.1043 & 5.85 & 0.109 & 5.79 & 0.1084 \\
\hline
\end{tabular}

The pigs were either treated as a single population (no sorting) or the lightest $10 \%, 20 \%$ and $30 \%$ of the population were fed a higher digestible $\mathrm{P}$, in comparison with the remaining of the population. The supply of dietary digestible $\mathrm{P}(\mathrm{g} / \mathrm{kg})$ was determined to meet the average digestible $\mathrm{P}$ requirements of the sorted and remaining population at the mid-point BW of each feeding phase.

reached by this study, as far as $\mathrm{P}$ excretion is concerned, would be affected by this.

As well as resulting in reduction in $\mathrm{P}$ excreted, increases in the number of feed changes resulted in effects on performance: increases in $A D G$, Pr and $P$ retained, and decreases in FCR. Again these effects were more substantial when the feeding regime changed from one to two phases, rather than from two to three phases. A further consequence of these regimes was the $\mathrm{CV}$ in the population for the performances characteristics considered was substantially reduced. This would have significant economic implications, as there are financial penalties associated with the variability of a batch of pigs at slaughter (Patience et al., 2002; Patience and Beaulieu, 2006). The increases in BW gain were relatively small but associated with very small errors, which suggest that it may be difficult to observe them experimentally. There are no comparable experiments in the literature, but Pomar et al. (2009 and 2011) simulated the differences in performance between a three phase feeding regime and meeting the digP requirements of the pigs individually through precision feeding. They suggested that there were no differences in performance between these two feeding regimes. This is likely to reflect the fact that a three phase feeding regime already met the requirements of a substantial number of pigs in the population, as suggested here. 
The increases in both $\mathrm{Pr}$ and $\mathrm{P}$ retained through increases in the number of feed changes most likely reflect some of the simplifying assumptions made by the model (Symeou et al., 2014a). In the deterministic model the relationship between $\mathrm{Pr}$ and $\mathrm{P}$ retention was set to be isometric, following the linear correlation found between these variables by Rymarz et al. (1982), Jongbloed (1987), Hendriks and Moughan (1993) and Mahan and Shields (1998). Therefore, when the pigs are unable to deposit $\mathrm{P}$ at the maximum rate because digP fails to meet their requirements, in the model they will at the same time fail to grow $\operatorname{Pr}$ at the rate defined by its genotype, even if the feed amino acid content is non-limiting. In reality, reduction in growth is not expected as a result of moderate P deficit. For example, NRC (2012) suggested that if pigs are undersupplied with $\operatorname{digP}$ by $>15 \%$ of their requirements, their growth will be negatively affected. Therefore, the model is likely to have overestimated the effect $P$ deficit on performance.

In addition to investigating $P$ excretion, we also investigated two more outputs of interest: the percentage of the population that met the digP requirements and the percentage of the population that were supplied $<85 \%$ of their digP requirements at a particular BW. Both outputs can be related to potentially negative effects of pig performance, as discussed above, but at the same time they may be relevant to animal welfare. Jensen et al. (1993) found that even small deviations meeting the requirements of pigs in amino acids can lead to significant increases in exploratory behavior and activity, and changes in posture. Consequently, Kyriazakis and Tolkamp (2011) have suggested that such failures in meeting the requirements of the pigs may lead to undesirable behaviors, such as behavioral vice (e.g. tail biting; Day et al., 1996). Increasing the number of phase feeding sequences resulted in an increase in the percentage of animals whose digP were met and a decrease in the percentage of population supplied with $<85 \%$ of their requirements at a particular BW. These may have consequences on the welfare of the animals as suggested above, over and above the effects in $\mathrm{P}$ excretion.

\section{Sorting according to $B W$}

The popular use of the all-in/all-out production systems implies that management is important at a group level. Variability within a batch of pigs may result in more time to clear a barn till restocking, or more financial penalties at slaughter. A strategy occasionally used by the pig industry to overcome these adverse effects is to apply sorting of the population of pigs into 'light' and 'remaining' groups and manage these two groups in different finishing pens (Tokach, 2004). Thus, the remaining group could be 'closed out' sooner and restock faster. Sometimes the lighter group can be fed a different feed in order to meet the different nutrient requirements from the remaining pigs. The question is what the consequences of this management strategy are in terms of $P$ excretion and performance.

The simulations suggest that although there are reductions in the cumulative P excreted when the strategy was applied, these were relatively small, when compared with the $P$ excreted by the unsorted situation. The cumulative P excreted reduced by $1.5 \%, 2 \%$ and $3 \%$, as the size of the light population increased from $10 \%$ to $20 \%$ to $30 \%$ of the total population, respectively. This resulted from increases in the $P$ excreted by the light population and decreases in the $P$ excreted by the remaining population. For all these simulations we assumed that the feed composition will change only once throughout the growing finishing period, which is equivalent to a two phase-feeding regime. In addition, the light pigs were maintained on the nursery feed for a longer period of time before they were switched over to the grower one.

When applying the above strategy the sorted pigs were fed according to the digP requirements of the average of the sorted populations. As a consequence the light pigs received diets of higher digP content and the remaining pigs received diets of lower digP content. The consequence of this was an increase in the performance of the light pigs, in terms of BW gain, Pr and P retained. However, there were smaller decreases in the performance of the remaining sorted pigs compared with the remaining pigs in the unsorted population. These arose from the fact that a smaller number of remaining pigs met their digP requirements throughout the simulation in the sorting scenario. Our findings contrast with those of O'Quinn et al. (2000) and Schinckel et al. (2005 and 2007) who suggested that sorting had no effects on the performance of the pigs in the sorted and unsorted populations. However, in these experiments both sorted and unsorted pigs were fed the same diets. Therefore, it is important to appreciate what is aimed to be achieved by any sorting practices. In the experiments of O'Quinn et al. (2000) it is likely that it was hypothesized that any effects on light pigs would arise from the absence of competition, which would put lighter pigs at a disadvantage (Hessing et al., 1994). In our experiment the aim was to reduce the $P$ excreted by the batch of pigs and hence a change in the feeding regime was also deemed necessary. The CV of the ADG for the sorted pigs increased by sorting, probably because the level of under and over supply of digP was larger in comparison with the unsorted group, where a large percentage of the population were underfed in digP.

As with phase feeding, the application of sorting decreased the percentage of the population that met the digP requirements and the percentage of the population that were supplied $<85 \%$ of their digP requirements at a particular BW decreased, but only for the light pigs. This was because the management regime met more closely their requirements as a whole. The converse was the case for the remaining pigs and was a consequence of the content of the feed offered to these pigs being lower when the populations were sorted rather than unsorted.

\section{Future model developments and implications}

As discussed above the model assumed that as soon as digP supply to an individual pig was reduced, both $P$ and $P r$ retention were penalized. However, bones can act as P storage that can be utilized at times of relatively small P deficiency (Henry and 
Norman, 1984; Hurwitz, 1996; DeLuca, 2008). For this reason, the current version of the model most likely overestimated the effect of the variation of $P$ intake on the animal performance. This aspect should be taken into account in further model development, for example specifying a threshold of $P$ deficit above which no growth reduction occurs. However, more quantitative data is needed for this purpose.

For practical reasons, the analyses in the current study were based on 500 model simulations. In terms of Monte Carlo simulation the number of simulations can be considered relatively small. As some of the differences observed in $\mathrm{P}$ excretion and performance by the management strategies applied are relatively small, it would be important to know if the effects are due to the population size considered. However, given the small standard errors associated with the simulated means, this seems unlikely. The simulations suggest that $\mathrm{P}$ excretion was higher when a feeding regime targeted the requirements of the first third of the period as opposed to targeting the requirements at the mid-point. As there is a common feeding regime between the phase feeding and the sorting strategies some comparisons between the two can be made; the common feeding regime being a two-phase feeding regime when the population of pigs was treated as a whole. Sorting according to BW reduced further the cumulative $\mathrm{P}$ excretion.

In general, the stochastic model developed here overcomes the usual criticisms applied on the limitations of deterministic growth and metabolism livestock models (St-Pierre, 2013). It is capable of considering the consequences of future management strategies that may develop to reduce $P$ excretion by population of pigs, such as those associated with precision livestock feeding.

\section{Acknowledgment}

This study was funded by the British Pig Executive (now Agricultural and Horticultural Development Board Pork) in the form of a PhD studentship to Vasilis Symeou.

\section{References}

Brossard L, Dourmad JY, Rivest J and van Milgen J 2009. Modelling the variation in performance of a population of growing pig as affected by lysine supply and feeding strategy. Animal 3, 1114-1123.

Coppoolse J, van Vuuren AM, Huisman J, Janssen WMMA, Jongbloed AW, Lenis NP and Simons PCM 1990. The excretion of nitrogen, phosphorus and potassium by farm animals, now and tomorrow (in Dutch). Dienst landbouwkundig Onderzoek, Wageningen, The Netherlands.

Day JEL, Kyriazakis I and Lawrence AB 1996. An investigation into the causation of chewing behaviour in growing pigs: the role of exploration and feeding motivation. Applied Animal Behaviour Science 48, 47-59.

DeLuca HF 2008. Evolution of our understanding of vitamin D. Nutrition Reviews 66, 73-87.

Doeschl-Wilson AB, Knap PW, Kinghorn BP and van der Steen HAM 2007. Using mechanistic animal growth models to estimate genetic parameters of biological traits. Animal 1, 489-499.

Emmans GC and Fisher C 1986. Problems in nutritional theory. In Nutrient requirements of poultry and nutritional research (ed. C Fisher and KN Boorman), pp. 9-39. Butterworths, London, UK.
Emmans GC and Kyriazakis I 1997. Models of pig growth: problems and proposed solutions. Livestock Production Science 51, 119-129.

Emmans GC and Kyriazakis I 2001. Consequences of genetic change in farm animals on food intake and feeding behaviour. Proceedings of the Nutrition Society 60, 115-125.

Ferguson NS, Gous RM and Emmans GC 1997. Predicting the effects of animal variation on growth and feed intake in growing pigs using simulation modelling. Animal Science 64, 513-522.

Forsberg CW, Phillips JP, Golovan SP, Fan MZ, Meidinger RG, Ajakaiye A, Hilborn D and Hacker RR 2003. The Enviropig physiology, performance, and contribution to nutrient management advances in a regulated environment: the leading edge of change in the pork industry. Journal of Animal Science 81, 68-77. Groesbeck CN, Goodband RD, Tokach MD, Dritz SS, Nelssen JL and DeRouchey JM 2007. Diet mixing time affects nursery pig performance. Journal of Animal Science 85, 1793-1798.

Han IK, Kim JH, Chu KS, Xuan ZN, Shon KS and Kim MK 1998. Effect of phase feeding on the growth performance and nutrient utilization in finishing pigs. Asian-Australasian Journal of Animal Science 11, 559-565.

Hendriks WH and Moughan JP 1993. Whole-body mineral composition of entire male and female pigs depositing protein at maximal rate. Livestock Production Science 33, 161-170.

Henry HL and Norman AW 1984. Vitamin D: metabolism and biological actions. Annual Review of Nutrition 4, 493-520.

Henry Y and Dourmad JY 1993. Feeding strategy for minimizing nitrogen output in pigs. In Proceedings of the first international symposium on nitrogen flow in pig production and the environmental consequences (ed. MWA Verstegen, LA Den Hartog, GJM Van Kernpen and JHM Metz), pp. 137. EAAP Publication, Wageningen, The Netherlands.

Hessing MJC, Schouten WGP, Wiepkema PR and Tielen MJM 1994. Implications of individual behavioural characteristics on performance in pigs. Livestock Production Science 40, 187-196.

Hurwitz S 1996. Homeostatic control of plasma calcium concentration. Critical Reviews in Biochemistry and Molecular Biology 31, 40-100.

Jendza JA and Adeola 0 2009. Water-soluble phosphorus excretion in pigs fed diets supplemented with microbial phytase. Animal Science Journal 80, 296-304.

Jensen MB, Kyriazakis I and Lawrence AB 1993. The activity and straw directed behaviour of pigs offered foods with different crude protein content. Applied Animal Behaviour Science 37, 211-221.

Jongbloed AW 1987. Phosphorus in the feeding of pigs. Effect of diet on the absorption of phosphorus by growing pigs. Thesis PhD, University of Wageningen, Wageningen, The Netherlands.

Kim CJ, Mullan BP, Selle PH and Pluske JR 2002. Level of total phosphorus, phytate-phosphorus, and phytase activity in three varieties of Western Australian wheats in response to growing region, growing season, and storage. Australian Journal of Agricultural Research 53, 1361-1366.

Knap PW 2000. Stochastic simulation of growth in pigs: relations between body composition and maintenance requirements as mediated through protein turn-over and thermoregulation. Animal Science 71, 11-30.

Knap PW and Rauw WM 2008. Selection for high production in pigs. In Resource allocation theory applied to farm animal production (ed. WM Rauw), pp. 67-82. CAB International, Wallingford, UK.

Knap PW, Roehe R, Kolstad K, Pomar C and Luiting P 2003. Characterisation of pig genotypes for growth modelling. Journal of Animal Science 80, E187-E195. Kyriazakis I 2011. Opportunities to improve nutrient efficiency in pigs and poultry through breeding. Animal 5, 821-832.

Kyriazakis I, Emmans GC and Whittemore CT 1990. Diet selection in pigs choices made by growing pigs given foods of different protein concentration. Animal Production 51, 189-199.

Kyriazakis I, Szyszka O, Stockdale EA, Johnson A, Wilson S, Penlington N and Edwards SA 2013. Can we reduce our current levels of phosphorous in pig diets without affecting their performance and health? The Pig Journal 68, 97-101.

Kyriazakis I and Tolkamp BJ 2011. Hunger and thirst. In Animal welfare (ed. MC Appleby and BO Hughes), pp. 44-63. CAB International, Wallingford, UK.

Lee JH, Kim JD, Kim JH, Jin J and Han IK 2000. Effect of phase feeding on the growth performance, nutrient utilisation and carcass characteristics in finishing pigs. Asian-Australasian Journal of Animal Science 8, 1137-1146. 
Lenis NP 1989. Lower nitrogen excretion in pig husbandry by feeding: current and future possibilities. Netherlands Journal of Agricultural Science 37, 61-70.

Lopes BJ, Moreira AJ, Kebreab E, SSMD S. Vitti, Abdalla LA, Crompton LA and France $J$ 2009. A model on biological flow of phosphorus in growing pigs. Arquivo Brasileiro de Medicina Veterinária e Zootecnia 61, 691-697.

Maguire RO, Sims TJ, Saylor WW, Brake J and Joern CB 2005. Dietary strategies for reduced phosphorus excretion and improved water quality. Journal of Environmental Quality 34, 2093-2103.

Mahan DC and Shields RG 1998. Essential and nonessential amino acid composition of pigs from birth to 145 kilograms of body weight, and comparison to other studies. Journal of Animal Science 76, 513-521.

NRC 2012. Nutrient requirement of swine. National Academy Press, Washington, DC.

O'Quinn RP, Dritz SS, Goodband RD, Tokach MD, Swanson JC, Nelssen JL and Musser RE 2000. Sorting growing-finishing pigs by weight fails to improve growth performance or weight variation. Journal of Swine Health Production 9, 11-16.

Patience JF and Beaulieu AD 2006. Variation in the finishing barn. Manitoba Swine Seminar. Retrieved February 4, 2014, from http://www.prairieswine.com/ pdf/2244.pdf

Patience JF, Zijlstra RT and Beaulieu D 2002. Feeding growing and finishing pigs to maximize net income. Advances in Pork Production 13, pp. 61-75. Retrieved February 12, 2014, from http://www.prairieswine.com/pdf/2369.pdf

Pomar C, Jondreville C, Dourmad YJ and Bernier FJ 2006. Effect of dietary phosphorus concentration on pigs' performance and the body retention of calcium, phosphorus, potassium, sodium, magnesium, iron and zinc of 20 to $100 \mathrm{~kg}$ of live weight pigs. Journées Recherche Porcine 38, 209-216.

Pomar C, Hauschild L, Zhang GH, Pomar J and Lovatto PA 2009. Applying precision feeding techniques in growing-finishing pig operations. Revista Brasileira de Zootecnia 38, 226-237.

Pomar C, Hauschild L, Zhang GH, Pomar J and Lovatto PA 2011. Precision feeding can significantly reduce feeding cost and nutrient excretion in growing animals. In Modelling nutrient digestion and utilisation in farm animals (ed. D Sauvant), pp. 327-334. Wageningen Academic Publishers, Wageningen, the Netherlands.

Pomar C, Kyriazakis I, Emmans GC and Knap PW 2003. Modeling stochasticity: dealing with populations rather than individual pigs. Journal of Animal Science 81, E178-E186.

Rivest J 2004. Epreuve 16. Performances des animaux en station. Rapport final. Evaluation des verrats terminaux: Duroc et P76. Centre de développement du porc du Québec, inc., Sainte Foy, Canada.

Rymarz A, Fanderjewski H and Kielanowski J 1982. Content and retention of calcium, phosphorus, potassium and sodium in the bodies of growing gilts. Journal of Livestock Production Science 9, 399-407.
Schinckel AP, Cabrera R, Boyd RD, Jungst S, Booher C, Johnston M, Preckel PV and Einstein ME 2007. Modelling the impact of birth and twenty-day body weight on the postweaning growth of pigs. The Professional Animal Scientist 23, 211-223.

Schinckel AP, Einstein ME and Miller D 2005. Evaluation of a method to analyze pig live weight data from animal sorting technologies. The Professional Animal Scientist 21, 50

Selle PH, Ravindran V, Cowieson JA and Bedford RM 2011. Phytate and phytase. In Enzymes in farm animal nutrition (ed. MR Bedford and GG Partidge), pp. 160-205. CABI Publishing, Wallingford, UK.

Simpson $\mathrm{G}$ and de Lange $\mathrm{K}$ 2004. Nutritional strategies to decrease nutrients in swine manure. OMAFRA Factsheet, Ontario, Canada. Retrieved January 12, 2014, from http://www.omafra.gov.on.ca/english/livestock/swine/facts/04035.htm

Statistics Canada 2006. Hog statistics, vol. 5, no. 4, catalogue no. 23-010-XIE. Statistics Canada, Ottawa, ON.

St-Pierre N. 2013. Statistical issues in nutritional modeling. In Nutritional modelling for pigs and poultry (ed. Sakomura NK, R Gous, I Kyriazakis and L Hauschild), pp. 62-73. CABI Publishing, Wallingford, UK.

Symeou V, Leinonen I and Kyriazakis I 2014a. Modelling phosphorus intake, digestion, retention and excretion in growing and finishing pigs: model description. Animal 8, 1612-1621.

Symeou V, Leinonen I and Kyriazakis I 2014b. Modelling phosphorus intake, digestion, retention and excretion in growing and finishing pigs: model evaluation. Animal 8, 1621-1631.

Tokach M 2004. Dealing with variation in market weight. Advances in Pork Production 15, 281-290. Retrieved December 12, 2013, from http://www. prairieswine.com/pdf/2423.pdf

Trujillo JHA, Lindemann MD and Cromwell GL 2010. Phosphorous utilization in growing pigs fed a phosphorous deficient diet supplemented with rice bran product and amended with phytase. Revista Colombiana de Ciencias Pecuarias 23, 429-433.

van Lunen TA 1994. A study of the growth and nutrient requirements of highly selected pigs. Thesis PhD, University of Nottingham, Nottingham, UK.

Wellock IJ, Emmans GC and Kyriazakis I 2003. Modelling the effect of thermal environment and dietary composition on pig performance: model logic and concepts. Animal Science 77, 255-266.

Wellock IJ, Emmans GC and Kyriazakis I 2004. Modeling the effects of stressors on the performance of populations of pigs. Journal of Animal Science 82, 2442-2450.

White PJ and Hammond JP 2006. Updating the estimate of the sources of phosphorus in UK waters. A Defra funded project WT0701CSF, UK. Available at randd.defra.gov.uk/Document.aspx?Document=WT0701CSF_4159_FRP.pdf 